\title{
Study on the Role of Combined "Listen and Sing" Perception Music Teaching in Kindergarten Music Education
}

\author{
Liu Lei \\ China West Normal University, Nanchong, Sichuan, 637002 \\ hunter2011@foxmail.com
}

Keywords: Listen and Sing; Kindergarten Music; Perception Music Teaching

\begin{abstract}
Early childhood music education music teaching is part of this early music education offers young children the opportunity to develop their musical talent, and it is what most adults can give to take care and nurture for children. In kindergarten music activities, the combined "Listen and sing" music perception can foster children's interest in music, increase the capacity of children to feel the music, to experience the taste of Chinese and American musical activities, improve children's performance of the musical creativity, so that children through the activities to healthy growth and harmonious development. Literature combined "listen and sing" perception music teaching on the creative aspects of early childhood culture made a more detailed discussion on the importance of child care or early childhood music education, I believe that the organization the combined "listen and sing" outstanding musical perception in early childhood music teaching effect, is a powerful tool for the comprehensive development of early childhood music talent, this paper attempts importance of rhythm in the early childhood music teaching and conducts specific analysis.
\end{abstract}

\section{Introduction}

Musical sensibility is what children learn music, the most important development of musical talent, most fundamental abilities. Which distinguish the intensity level of the sound, the length of the sound, the sound is a fundamental task of the kindergarten musical knowledge and skills instruction. Dahl Klose said: "The music itself is auditory-based music education should be based entirely on listening." Thus, the rhythm of the music teaching should listen to the main line. On the basis of listening to the teacher with concise, accurate, vivid and instructive language, pictures, audio-visual aids to inspire children's imagination and help them to have awareness and understanding of music. In young children are familiar with the music in the process, step by step guide them to do the clapping, nodding, running and other movements, or inspire them to do a simple impromptu performances. Thus, not only to help them to master the rhythm of music, rhythm, but also enlighten their musical sensibility and expressive, let them into the musical mood. After years of kindergarten music teaching, I found the rhythm to compile clever sense of music students can effectively develop students' ability to feel the music.

\section{Combined "Listen and Sing” Perception Music Teaching is an Important Way to Cultivate Children's Musical Aesthetic Force}

Rhythm is a need for imagination and creativity activities, under the music for the infection, the body with undulating melody freely rich body dynamic rhythm, rhythm, and it is the music and the physical and mental sensing and motion close binding. Early childhood music teaching organization Combined "Listen and Sing" Perception Music Teaching, not only help children to experience and understand musical works, and it helps to stimulate interest appreciate, accumulating musical aesthetic experience, improve the aesthetic quality, broaden musical horizons, which students good music quality, and ultimately achieve the purpose of educating people. As Mr. Park that said: "The music is by providing discipline inherent in the nature of music itself, that is to bring a sense of fulfillment in life aesthetic experience-music experience to realize they assume the role of a personality forming aspects. Children's aesthetic psychological structure mainly includes a keen 
perception, imagination, a thorough understanding other aspects. Foster children aesthetic ability is a necessary condition of art appreciation and art activities is to develop rich musical performance active power and creativity base, is an important means to accumulate wealth inherent emotions. So how to train children in kindergarten keen have aesthetic ability rhythm and to teach it?

From Appreciation, Guide start and Develop a Keen Aesthetic Perception. First, it is the creation of the environment, the influence of the infection. Preschool teachers to be more interested in creating an environment to stimulate early childhood music, while taking advantage of children curious, playful and psychological characteristics, to every aspect of music teaching fun, life. Teachers must pay attention to the material provided so that children are interested in, it is easy to memorize and young children, promote the development of early childhood memory. Facts have proved that: If the task of memorizing the motivation and interest in events and activities linked memorizing and memorizing the positive effects can be greatly improved. create an aesthetically pleasing environment, can stimulate children's interest in the things of beauty, so that their aesthetic perception in a positive, active state. My approach is to day activities permeate the rhythm of music, induce children's interest in music. For example: In the morning, when the children have finished breakfast, I play soft music, let them do some brisk walking rhythm into the activity room, when children hear "sieve opening song" This song, will be excited to sing hand pretending to take the cup like tooth edge performances, the song became interested in children. They have great enthusiasm and a high degree of attention to listen, to touch, to feel happy and cheerful mood songs. At the same time, we also clever use of some spare time, such as before a nap, Dining, music and other centralized teaching time ago to play or let the children play various types of performances to some beautiful rhythm. Over time, the children listen to slowly raise interest kids monasteries close to music, familiar music, so fond of music, feel the music, now the kids no matter what the occasion, whenever they hear the music, the songs, they will dance, enjoy themselves.

Secondly, to strengthen the work choices, broaden horizons aesthetic Goethe once said:. "Appreciation not by works but by ornamental medium works best in order to develop into a" So, first provided to the child should be some of the finest music material. Secondly, we must carefully design aesthetic of rhythm action. Organized systematically organize teaching rhythm to help children perception experiences systematic, so as to nurture their keen aesthetic perception. Migrate existing aesthetic experience evoked rich aesthetic imagination.

Imagination refers to mind the appearance of existing processing transformation process to create a new image. Imagination is the most essential connotation of creativity, no imagination, creativity means poor. Early childhood is the most active period of the imagination, the imagination of children is children to explore activities and innovative activities on the basis of all innovation activities are creative imagination from the start. Music image is a widespread mood of the music vivid imagination, and music education is through music image, arouse children related visual impression, the auditory impression and association related things, in order to develop their imagination. Learn to sing songs, enriched the children's oral language; learning rhythm, early childhood development action language, "and the children's language development, imagine intentional, self-awareness, the more general and logical development". So music education is for the development of children's imagination.

Emotional start, Improve the Aesthetic Understanding. Children are fond of art starting from emotion, their interest in the arts exhibits are shallow, often with a certain emotional color, easy to stay in the fun. I like the level, and very easy to transfer fluctuation. Therefore, according to the accumulation of life children, memory storage, imagination are not the same, the choice of music (song) song, the children should be taken into account is easy to understand, and has a distinctive characteristic rhythmic music. Or the performance of the quiet, serene lullaby; or performance dashing high spirits march; or a cheerful, lively dance music to inspire children the appropriate mood, association and creativity. Such as: use some to jump tone based song, children performances, the children will soon feel the music lively, jumping characteristics, showing the form of animal bunny hopping, frogs, kangaroos and so on. Another example: the children cannot help but dance in some gentle and beautiful music, the performance of butterflies, fish playing in 
the water, the wind swinging willow leaves. Kids will remember the music and open windows, expand the wings of imagination, listening, feel and experience the music, while promoting early childhood imagination and the life of all beautiful things, so as to nurture cultivate children's beauty and personality as a teacher, we should give full play to the guiding role, select some excellent music works, to fully tap its aesthetic factor, then according to the level of aesthetic interest and aesthetic children, rhythm action designed to stimulate children emotion, and gradually improve their aesthetic understanding.

\section{Combined "Listen and Sing" Perception Music Teaching is the Main Way to Develop Children's Musical Expression.}

Features rhythm teaching is closely combined with the feelings and body movements to music together, it produces better teaching results. Because music is a performing arts appeal to emotion. Therefore, the language of rhythm and music with emotional language is important. Rhythm is designed based on the analysis of teaching materials and music emotions, according to the characteristics of materials to design. Light and lively dance, action inevitable crisp design, showing a cheerful mood; beautiful soft ballad, its action should highlight the express exhibition; according to folk music have different ethnic customs and style design, should With the folk dance language so that the rhythm of penetration national characteristics. Children in a pleasant "Listen to sing" The combination of music perception, by teachers in "Listen to sing" The combination of a positive perception of music created by music mood, expand the imagination, the freedom to use body movements to reflect the strength of the music rhythm, speed, enjoy expressing their emotional experience, improve early childhood musical expression.

\section{Conclusion}

Music education is to improve the quality of early childhood psychology, to promote early childhood intellectual development, and enhance the health of children, and it is an effective means to enrich children aesthetic emotion. Children need music and children live without music is unthinkable. Because music can inspire people, give people inspiration and strength, although only a simple rhythm, but also give children the joy of beauty, improve their spiritual realm. When the children performed a rhythm as they want to concentrate on listening to music, rhythm and accurate, performing his own tacit understanding that the most graceful movements, their emotions can be happy, quiet with the music, as if the whole body and mind is poured into the musical mood. After a planned step rhythm training, children will become familiar with the music, understand music, on this basis, the music will become a spiritual soul of the children. Children will also be enhanced in this beautiful feeling in the music sensibility, aesthetic power, expressiveness and creativity.

\section{References}

[1] Yi-Li Y. Kindergarten Teacher Professional Philosophy and Morality, Content and Generate . Preschool Study,2012 (9): 3-11.

[2] Xu-Zuo Y. Happy Music Education in a Nursery to Observe the Eighth National Seminar Heat Point Question and Answer. Early Childhood, 2013 (4): 10-12.

[3] Cheng-Xiao M. Analysis and Recommendations to the Central Government Policy Documents Related to Early Childhood Education . Preschool Research Study, 2014 (1): 36-42.

[4] Qin F. Kindergarten Teaching the Game of Musical Album a Jasmine. Early Childhood Education, 2003 (4): 23-25.Zhang Ling Liu Jiqiu study..

[5] Zhang L. Children's Music Education in Country Several Key Problems. Sports and Arts Surgery, 2009 (12): 330-330. 